\title{
Granular Cell Tumor of the Tongue: A Case Report with Emphasis on the Diagnostic and Therapeutic Proceedings
}

Bacem AE Ottoman*

${ }^{1}$ Department of Medicine, Division of Hematology/Oncology, Beth Israel Deaconess Medical Center, Harvard Medical School, Boston, MA, USA

${ }^{2}$ Department of Pathology, Beth Israel Deaconess Medical Center, Harvard Medical School, Boston, MA, USA

\begin{abstract}
Granular cell tumor (GCT), eponymically Abrikossoff's myoblastoma, is an uncommon asymptomatic benign neoplasm with controversial etiopathogenia. The tumor typically reveals itself as a well-circumscribed, slowly growing nodular mass. Tongue is most commonly preferred in the head and neck region. The conventional size of the granular cell tumor is usually measuring 2-3 centimeters in its greater diameter. The granular cell tumor can taint all age groups, with a peak between 40 and 60 years. This report introduces, however, a case of GCT of the tongue in a much younger female that was totally excised. The clientele has shown up after 1, 3 and 6 months for follow-up. In the head and neck region, there was no evidence of either recurrence or metachronous clinical manifestations of any similar lesions; at the clinical and sonographical assessment.
\end{abstract}

Keywords: Abrikossoff's tumor; Granular cell tumor; Myoblastoma; Tongue ultrasound

\section{Introduction}

In 1926, Alexei Ivanovich Abrikossoff has introduced the granular cell tumor (GCT), designating it as a myoblastoma. GCT is an uncommon asymptomatic sessile nodule with typical pink overlying mucosa. For its idiopathic and controversial histogenesis, over claims of its muscular, histiocytic, fibroblastic or neural origin, it was advocated to use the noncomittal designation of GCT. In the head and neck, anterior tongue is mostly affected [1]. GCT has a remarkable epidemiological predilection of which it affects females as twice as it hit male By the same token, there seems an impressive inclination of GCT to be encountered in the older population especially the black ethnic groups 'by a ratio of 3:1. The classical treatment of granular cell tumor is surgical. Conservative excision with safety margins is aimed; yet, the complete excision cannot be overemphasized. GCT should not be confused with congenital epulis of the newborn (CEN), which display histologically an impressive granularity, simply because the latter is not a true neoplasm and incurs neither recurrence nor malignant transformation, even if not adequately excised. Characteristic to CEN is its involution. The differential diagnosis of GCT of the tongue includes numerous benign mesenchymal tumors such as neurofibroma, ossifying fibromyxoid tumor, lipoma, chondroma, fibroma, neuroma, and schwannoma [1-3]. Nonetheless, GCT could be diagnosed in pediatric populations [4]. This paper reports, however, a very young age affection of GCT in a white 17 -year-old girl. This uncommon find should capture the clinicians' rapt attention to including GCT in the differential diagnosis in such newly reported epidemiology.

\section{Case Presentation}

A 17-year-old female visited our Department of Maxillofacial Surgery with a small elevated nodule on the anterior dorsal surface of the tongue. The lesion appeared insidiously. An intra-oral examination revealed a pink nodular, sessile lesion of a firm consistency, whose texture was almost normal. The size of the nodule was about $2 \mathrm{~cm}$ in diameter, and was totally asymptomatic (Figure 1). A wide excisional biopsy was performed, under local anesthesia, based on the tentative diagnosis of (neuro) fibroma, or GCT. The sonographic benign picture of both lesion and regional lymph nodes were supportive. The ultrasound study revealed a well-defined hypoechoic lesion just beneath the tongue surface. Lymph nodes expressed normal sonographic oval picture with

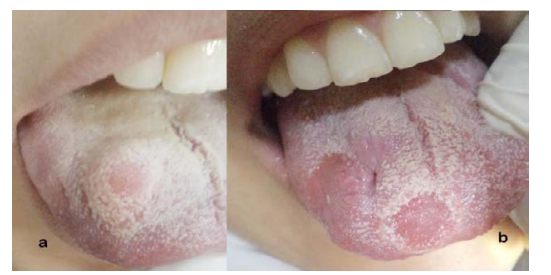

Figure 1: (a) Clinical picture of the lesion before excision (b) Clinical picture of the lesional site, 3 weeks after excision

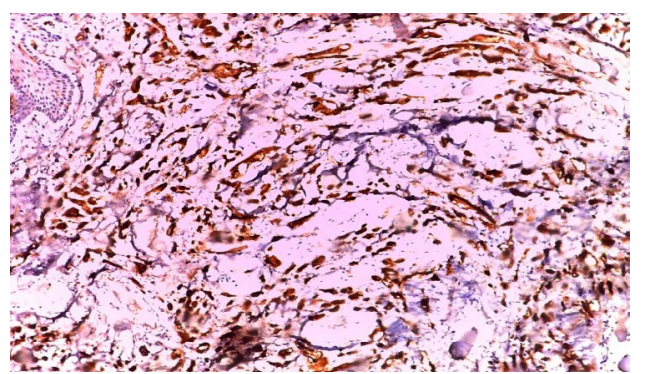

Figure 2: Photomicrograph showing elongated rete pegs of the pseudohyperplastic epithelium and dominantly intervening granular cells. (H\&E stained, Original magnification 10x).

preserved hilum. The Doppler interrogation showed no abnormality. Microscopic analysis revealed a neoplastic lesion whose hallmarks were the impressive granular cells and pseudoepitheliomatous hyperplastic epithelium (Figures 2 and 3). The lesional granules showed a strong

*Corresponding author: Bacem AE Ottoman, Diagnostic Pathology and Molecular Oncology, Cairo University, Cairo, Egypt, Tel: +20 235676105 E-mail: bacemottoman@gmail.com

Received: November 19, 2015; Accepted: December 03, 2015; Published: December 07, 2015

Citation: Ottoman BAE (2015) Granular Cell Tumor of the Tongue: A Case Report with Emphasis on the Diagnostic and Therapeutic Proceedings. Oncol Cance Case Rep 1:106.

Copyright: ( 2015 Ottoman BAE. This is an open-access article distributed under the terms of the Creative Commons Attribution License, which permits unrestricted use, distribution, and reproduction in any medium, provided the original author and source are credited. 


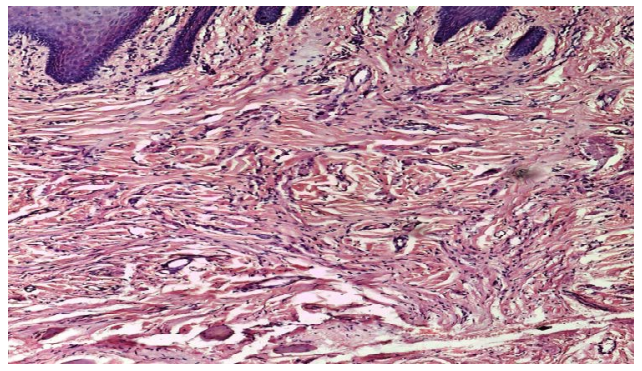

Figure 3: Photomicrograph displaying the granular cells which interlace with the collagen fibers of the existing muscle. (H\&E stained, Original magnification: 40x)

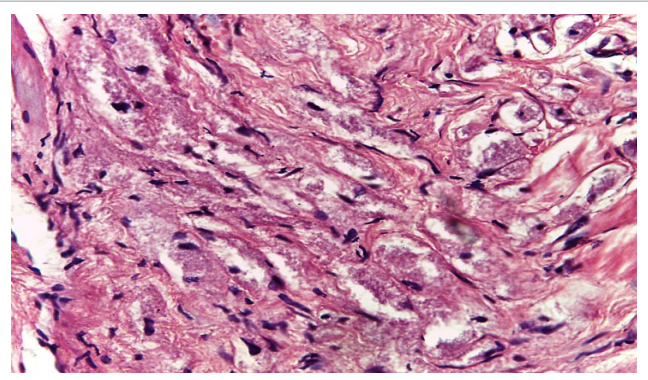

Figure 4: Photomicrograph characterizing the strong immunoreactivity of the granular cells for S-100. (Original magnification: 40x).

positivity for both S-100 (Figure 4) and Periodic acid-Schiff (PAS)reaction. Hence, the established histologic diagnosis was GCT.

\section{Discussion}

Granular cell tumor is a rare tumor that can affect various regions of the body, such as skin, soft tissues, breast, nervous system, gastrointestinal tract, urinary bladder and lungs [3-5]. Granular cell tumor can manifest, furthermore, as a solitary lesion or multiple synchronous lesions especially in the upper aerodigestive tract. In the head and neck region, which represents $45 \%$ to $65 \%$ of all the involved sites, GCT is encountered most commonly in the oral tongue, especially on its anterior one third [5-7]. Clinically, benign GCT manifests as a nodular pink firm lesion that rarely exceeds $3 \mathrm{~cm}$ in diameter. The patient is not necessarily aware of the insidious onset because it is totally asymptomatic and usually interfering with no functions $[1,8]$. Microscopically, GCT displays plump eosinophilic cells whose cytoplasm evinces rich granularity. The cells, either polygonal or elongated, recapitulate a syncytial pattern. Being essentially unencapsulated, the granular cells, most often, infiltrate into the adjacent tissues; typically skeletal muscles. Similar configuration of granular cells can be conspicuous near to the epithelium, often forming small anastomosing, or even sporadic, islets at the interface of the connective tissue and epithilum. Interestingly, most cases display a marked pseudoepitheliomatous hyperplasia which might be dysmorphic, to some pathologists, to suspect squamous cell carcinoma (SCC). Immunohistochemically, GCT expresses strong positivity for S-100 protein, unlike CEN which is typical of neural tumors. GCT reveals positive immunoreactivity for CD57 and type IV collagen $[1,5,8]$. Given this diagnostic challenge, cases of GCT should be well-investigated. Complicating matters, some cases of SCC of the tongue were recently reported in association with the benign GCT [9-11]. In a similar vein, a crucial distinction must be made between GCT and CEN. Similar to GCT, CEN can be manifest synchronously in multiple numbers [12], even at the same site [13]. However, CEN can resolve by its own or at minimal surgical intervention, including simple incision or excision [14]. Nonetheless, GCT has also shown a metachronous appearance [15]. Recurrences of GCT, contrary to CEN, may occur following an inadequate excision [1,8]. Moreover, GCT has been reported to undergo a malignant transformation been reported in $10 \%$ of the reported cases of which $1-2 \%$ of cases evinced a distant metastasis. In such cases, radiochemotherapy is recommended $[2,16,17]$. Pertinently, careful consideration and confirmatory investigations are highly advocated to exclude any liable malignancy. For metachronous occurrence, there appears no agreement, in the literature, either on the follow-up interval or the vital structures to be assessed. Based on the second most frequent site and the striking female predilection, females, with history of GCT, are recommended to run a sonographical assessment on the site of surgery for tracing recurrence, and breast. Surgical excision, with safety margins, is the mainstay treatment for GCT, although this is not always possible because the tumor is non-encapsulated, the histologic examination can confirm or defy the freeness or marginal positivity if the specimen was correctly labeled $[1,7]$.

\section{Conclusion}

Granular cell tumor, though uncommon, needs to be revisited systematically on the clinical, sonographical, histological, and immunohistological levels. Patients must be educated about the liability of metachronicity of this disease, and significance of close follow up. Clinical long-term surveillance and ultrasound scan at both the surgical site and the breast should be annually performed in females with history of GCT.

\section{Consent}

For publication of this case report and any accompanying images, a written informed consent was obtained from the patient and her guardian, according to the national law. A copy of the written consent is available for review by the Editor-in-Chief of this journal.

\section{References}

1. Neville B, Damm D, Allen C, Bouquot J (2009) Oral and maxillofacial pathology $\left(3^{\text {rd }}\right.$ edn $)$, Elsevier, Philadelphia, USA.

2. Sposto M, Navarro C, de Andrade C (2006) Granular cell tumour (Abrikossoff's tumour): Case series. Oral Oncol Extra 42: 194-197.

3. Suchitra G, Tambekar K, Gopal K (2014) Abrikossoff's tumor of tongue: Report of an uncommon lesion. J Oral Maxillofac Pathol 18: 134-136.

4. Nagaraj P, Ongole R, Bhujanga Rao B (2006) Granular cell tumor of the tongue in a 6 year old girl- a case report. Med Oral Pathol Oral Cir Bucal 11:E162-4.

5. Speight P (2005) Granular cell tumor. In World Health Organization Classification of Tumours. Pathology and Genetics. Head and Neck Tumours IARC Press 185-186.

6. Becelli R, Perugini M, Gasparini G, Cassoni A, Fabiani F (2001) Abrikossoff's tumor. J Craniofac Surg 12: 78-81.

7. Costa N, Bertini F, Carvalho Y, Almeida J, Cavalcante A (2012) Granular cell tumor presenting as a tongue nodule: Two case reports. J Med Case Rep 6: 56

8. Regezi J, Sciubba J, Jordan R (2007) Oral Pathology. ( $5^{\text {th }}$ edn), Clinical Pathologic Correlations, Saunders, Philadelphia, USA.

9. Altabiano R, Cappellani A, Di Vita M, Lanzafame S (2008) The unique simultaneous occurrence of a squamous cell carcinoma and a granular cell tumor of the tongue at the same site: a histological and immunohistochemical study. J Craniofac Surg 19: 1691-1694.

10. Bedir R, Yilmaz R, Sehitoglu I, Ozgur A (2015) Coexistence of Granular Cell Tumor with Squamous Cell Carcinoma on the Tongue: A Case Report. Iran J Otorhinolaryngol 27: 69-74.

11. Son H, Kim J, Ko G, Lee E, Woo S (2012) Lingual Squamous Cell Carcinoma Surrounded by Granular Cell Tumor. Chonnam Med J 48: 65-68. 
Citation: Ottoman BAE (2015) Granular Cell Tumor of the Tongue: A Case Report with Emphasis on the Diagnostic and Therapeutic Proceedings. Oncol Cancer Case Rep 1:106.

Page 3 of 3

12. Saki N, Araghi S (2014) Multiple congenital epulis in alveolar ridges of maxilla and mandible in a newborn: a rare case report. Case Rep Otolaryngol.

13. Liang Y, Yang YS, Zhang Y (2014) Multiple congenital granular cell epulis in a female newborn: a case report. J Med Case Rep 8: 413.

14. Ottoman B (2015) Diagnosis and Management of Congenital Epulis of the Newborn: a rare case report and literature review. Int J Sci Rep 1: 80-82.

15. Vera-Sirera B, Zabala P, Aviño-Mira C, Vera-Sempere FJ (2014) Multiple granular cell tumors with metachronous occurrence in tongue and vulva Clinicopathological and immunohistochemical study. J Oral Maxillofac Patho 18: $437-441$

16. Fanburg-Smith J, Meis-Kindblom J, Fante R, Kindblom L (1998) Malignan granular cell tumor of soft tissue: diagnostic criteria and clinicopathologic correlation. Am J Surg Pathol 22: 779-794.

17. Krishnamurthy A, George R, Majhi U (2014) Malignant granular cell tumor of the tongue: a clinico-pathological challenge. Indian J Surg Oncol 5: 71-74. 